\title{
Reality Gaps in Industrial Engineering Senior Design or Capstone Projects
}

\section{Desen Sevi Ozkan, Virginia Tech}

Desen is a PhD student in Engineering Education at Virginia Tech. Prior to studying at VT, she worked in the Biosystems engineering department at the University of Tennessee, Knoxville as a research assistant focusing on wastewater engineering and water reclamation. Desen holds a B.S. in Chemical Engineering from Tufts University and is on track to completing her M.S at Virginia Tech. She was born in Arlington, Texas, then moved to Istanbul, Turkey, and then to Boston to pursue her B.S. She speaks Turkish fluently. $\mathrm{Her} \mathrm{PhD}$ focus is on creativity and design in engineering education. When not studying or teaching, Desen is riding her bikes up and especially down the mountains of Southwest Virginia.

\section{Dr. Homero Gregorio Murzi, Virginia Tech}

Homero Murzi is an Associate Professor of Practice in the Department of Engineering Education at Virginia Tech. He holds degrees in Industrial Engineering (BS, MS), Master of Business Administration (MBA) and in Engineering Education (PhD). His research focuses on contemporary and inclusive pedagogical practices, environmental, ethics and humanitarian engineering, and non-traditional knowledge transfer. Homero has been recognized as a Fulbright scholar and was inducted in the Bouchet Honor Society.

\section{Dr. Alejandro Salado, Virginia Tech}

Dr. Alejandro Salado is an assistant professor of systems science and systems engineering with the Grado Department of Industrial \& Systems Engineering at Virginia Tech. His research focuses on unveiling the scientific foundations of systems engineering and using them to improve systems engineering practice. Before joining academia, Alejandro spent over ten years as a systems engineer in the space industry. $\mathrm{He}$ is a recipient of the Fabrycky-Blanchard Award for Systems Engineering Research and the Fulbright International Science and Technology Award. Dr. Salado holds a BSc/MSc in electrical engineering from Polytechnic University of Valencia, an MSc in project management and a MSc in electronics engineering from Polytechnic University of Catalonia, the SpaceTech MEng in space systems engineering from Delft University of Technology, and a $\mathrm{PhD}$ in systems engineering from the Stevens Institute of Technology. $\mathrm{He}$ is a member of INCOSE and a senior member of IEEE and IIE.

\section{Chris Gewirtz, Virginia Tech}

Chris Gewirtz is PhD student in Engineering Education at Virginia Tech. His research interests start with how culture, history and identity influence assumptions made by engineers in their practice, and how to change assumptions to form innovative and socially conscious engineers. He is particularly interested in humanitarian engineering, where many traditional engineering assumptions fall apart. 


\title{
Reality Gaps in Industrial Engineering Senior Design or Capstone Projects
}

\begin{abstract}
Undergraduate Senior Design or Capstone Projects (SDP) are intended to provide a culminating experience for undergraduate students. In SDP's, students are expected to put into practice their engineering competences to solve a realistic problem. Realism is pursued by setting up boundary conditions that mimic to some extent those found in the corporate world. For example, projects are defined by an external company that acts as a sponsor or client, last between one and two semesters, are carried out in teams, and, in some cases, are vaguely defined. Moreover, students are often requested to complete various stages of the system's life cycle, including formulating the problem, conceptualizing the solution, implementing a solution in part or whole, and presenting the solution to the client. However, while these project conditions provide a decent surrogate of a real industrial problem, students' solutions are purely academic: They lack key elements that any engineering solution to a real problem should have. For example, students' solutions tend to be deterministic, assume seamless implementation and adoption, do not create unintended consequences, and are free of risks. Furthermore, these weaknesses are not identified in the evaluation of projects because assessments remain academic. They focus on evaluating if industrial engineering tools and methods have been properly used, and if the development process described in class has been followed. However, evaluating the value of an engineering solution in the corporate world is driven by the identification of worst- and best-cases, the contextualization of the solution within ranges of expectation, the assessment of impacts of implementing and adopting the solution, and the identification of the solution's potential unintended consequences and resulting risks. In order to contribute to close this gap between industry and academia, we characterize in this paper SDP's in industrial engineering undergraduate programs across the USA. In particular, we identify the aspects of real engineering projects that are captured, and those that are missing, in the problems that students solve, and are exhibited in the solutions they create. Then, we use the results to define a set of guidelines that would contribute to improve the realism of SDP's, both in terms of their problem definition and of the evaluation and assessment of students' solutions.
\end{abstract}

\section{Introduction}

Research suggests that engineering education and practice are disconnected [1]. In particular, early career engineers believe that "engineering work is much more variable and complex than most engineering curricula convey" [2]. Successful engineering, in practice, is driven by the skills necessary to solve open-ended, ill-structured problems, such as problem formulation, communication, people management, decision-making, negotiation, and conflict resolution, among others [2-6]. However, engineering education continues to focus on the use of equations and theories to solve well-structured problems [7].

We share the experience that "exposing senior engineering students to problems that resemble the ambiguity and social characteristics of engineering practice reveals student difficulties in bounding, coping, and navigating through the ambiguity of problem definition" [8]. We also share the belief that, "while engineers will eventually acclimate to this context during 
their early careers as practitioners, ... engineering education can be adapted to help our students gain those skills as they learn traditional concepts, theories, and analytical methods" [8].

The focus of this paper is Undergraduate Senior Design or Capstone projects (SDP). An SDP is a culminating experience for undergraduate students, usually taking place during their last year of studies in the US education system. Their intent is to allow students to put into practice the engineering competences that they have acquired during their studies to solve a realistic problem. However, we contend that most programs center on establishing realism through the definition of the problem, and miss evaluating the realism exhibited by the solutions students develop.

In order to study this gap further, this paper investigates whether the solutions that students develop as part of their SDP's poses characteristics that are considered critical in authentic settings. We focus on three key characteristics, derived from over two decades of professional experience of two of the authors in this paper:

1) Express solutions stochastically. Students tend to provide deterministic solutions, that is, they are expressed in the form of a single number. For example, we have seen students declare that their solution "reduces the distribution time by $20 \%$, resulting in savings of $\$ 135,422$." However, realistic problems are subjected to uncertainty and a good realistic solution must be always expressed in the form of a range. A pragmatic way in which students could work with stochastic processes is for example identifying worst-case, best-case, and nominal case. Hence, a realistic solution to the previous example would have been expressed as "a time reduction between $15 \%$ and $22 \%$ (nominally $20 \%$ ), which results in cost savings between $\$ 120,000$ and $\$ 143,000$ (nominally $\$ 135,422$ )."

2) Factor in implementation and adoption effects. Several solutions in industrial engineering SDP address process improvement. Students present the value of their solution by describing the future performance of the system, after their solution has been implemented. However, every process change requires an implementation and adoption effort, which is in several cases non-negligible. In fact, even with the best process improvement design, the solution may radically fail if not organically adopted by the people using or contributing to the process. Yet, students consider implementation and adoption to be seamless. Therefore, a realistic solution of this type will always factor in the effects of implementation and adoption to holistically measure the actual improvement that the solution could attain. For example, instead of describing the effectiveness of a solution as a comparison between the future state and the current state, a realistic solution describes at least the deployment plan, incorporating assumptions and risks, identifying feedback loops, as well as quantifying the necessary investment and incorporating it as a depreciation in the effectiveness of the future state.

3) Every solution to a problem creates new problems. Not only do students assume that the implementation and adoption of their work will be seamless, they also believe that the reach of its consequences will be limited to the improvement they aim to achieve. In other words, they consider, usually unwarily, that their solutions behave as a closed system within the boundaries they have defined. They are unaware of connections between their solution and the larger system that they have 
not captured. As a result, students do not explore or try to identify if, once implemented and adopted, their solution creates problems that did not exist previously. However, it is known that every solution creates new problems. In fact, literature shows plentiful of cases where solutions created problems that were more critical than the initial problem they solved (e.g. (Buede, 1998; Lehmann, Seroussi, \& Jaulent, 2016)). Nevertheless, a key aspect of engineering is not to design a solution that does not create a new problem, but to make sure that the new problems are less critical than the old ones. For example, we have seen students working on minimizing drug waste at a hospital pharmacy, without considering the impacts that such changes in drug stockage could have on service level.

This paper addresses the research question, do solutions in SDP incorporate aspects of authentic engineering? We performed a qualitative analysis of 52 SPD's in industrial engineering in 4 different institutions. We used the results to derive a set of guidelines that could be useful to redefine the rubric for evaluating SDP's.

\section{Background}

This section will draw from the existing literature in order to frame our approach to data analysis and provide background to understand Senior Design Projects.

Ill-defined Problems. Problems that students solve can be well-defined, or ill-defined problems - with these two properties falling at opposite ends of a spectrum [7]. Well-defined problems have many or all of factors that affect the problem accounted for in its description, and generally well-defined problems have one correct solution. Ill-defined problems include multiple contextual factors in the description of the problem. These contextual factors can include environmental contexts, societal contexts, or even multiple constraints that must be balanced with the technical aspects of the problem for a solution. Contextual factors make the problem ill-defined because their effect on the solution is not defined for students, and they must discover or predict (and they cannot predict with absolute accuracy) what the effects will be in the course of solving the problem [7]. The ability to solve ill-defined problems, which are representative of real-world problems that professional engineers face in their work, is desired in students entering the industrial engineering workforce [9].

Supporting learning with ill-defined problems prepares students for professional work by adding a layer of real-world uncertainty to technical problem solving. Ill-defined problems help develop students problem-solving skills, as well as their creativity, in ways that well-defined problems do not do $[10,11]$. For example, well-defined problems have exact answers and rely on the use of multiple known formulas. One example of an ill-defined problem that Litzinger et al. borrow from Christensen involves students predicting the impact and number of victims of the bird flu if it were to come to Demark [10]. Students cannot calculate the answer, rather they must estimate it. Moreover, the estimation is not based on taking known formulas and reusing them, but requires students to do background research (how is bird flu spread? How effective are mitigation techniques?), to extrapolate from known scenarios (how has bird flu spread in other places?), and to make connections where there previously were none (what will be different if bird flu comes to Denmark?). Our study addresses if students are able to identify, recognize, and frame problems that are presented as ill-defined ones within a realistic setting. 
Problem Definition. While problem solving is an important skill, it is distinct from problem definition. Problem definition, also known as problem setting, involves understanding the nature of a problem before or while attempting to solve it. It is a process that involves understanding the context of the solution, its stakeholders, and what their motivations are, listening to those stakeholders, and recognizing how the problem may require new approaches, assumptions or even disciplines to be solved $[10,11]$. Problem definition is an important part of solving complex "real world" problems, and is desired from students on the path to become industrial engineers. Thus, it is important to assess the extent to which students demonstrate an understanding of the larger context in which a problem is defined, such that their problem-solving methods are informed by situational features of the problem.

Problem definition gives engineers the opportunity to check assumptions that may be inappropriate, for instance, assumptions about what the stakeholders priorities might be, or about what kind of solution would be acceptable [13]. The ability to define problems is an important skill for holistic engineers, engineers that can look beyond narrowly defined disciplinary knowledge [14]. Problem definition varies with cultural background, and recognizing and negotiating problem definition between cultures is an important aspect of engineering in general [15]. Our study studies instances of students defining their problem in their design reports.

Unintended Consequences \& Savior Complex. While students have intentions, goals and design criteria for their senior design projects, the results of their project may not be as intended. Students may hold beliefs of engineering "normative holism", the idea that all engineering activity is beneficial to humanity by default [16]. They may hold these ideas about their projects even when their projects have limitations or even potentially cause harm, as is seen in many engineering projects, particularly engineering for development. Students may assume that their efforts have positive consequences without endeavoring to assess the consequences, particularly the social consequences, of their designs. Understanding that projects may have unintended consequences is an important aspect of professional industrial engineering, and is crucial to mitigating harm. This importance inspires us to look for the presence of unintended consequences (and the acknowledgement of potential consequences) in student's descriptions of their projects.

The lack of recognition of unintended consequences goes hand-in-hand with the concept of "Saviour Complex", sometimes specified as "White Saviour Complex". Saviour Complex is the belief that one is uniquely poised to help those "who cannot help themselves," and is characterized by a lack of trust in those who are "helped" [17]. This positioning of oneself as someone to "lift" others up can accompany white privilege, though for this study, because racial identity is not deeply explored, it is associated more broadly with engineering identity (and simply referred to as "Saviour Complex").

While these two aspects of engineering problem solving may be present in senior design projects, the intent is not simply to criticize but to understand and correct these features of engineering design. Preparing students to understand the social contexts of the technologies they contribute to, requiring students to define problems by listening to stakeholders, and prompting them to critically reflect on their work, can all reduce their Saviour Complex and the unintended 
consequences of their designs [19, 20]. Our study codes for instances of both unintended consequences and evidence of Saviour Complex.

\section{Methods}

To answer our research question, data were collected qualitatively. The purpose of this exploratory study was to shed light on the learning outcomes of senior design projects to obtain a better understanding of the types of solutions that students develop in their projects across several higher education institutions. The study specifically targets senior design projects in the industrial engineering department, which includes system development or analysis, manufacturing, and operations research. Reports, posters, and presentations have been collected from the respective Industrial Engineering program leads through a recruitment email. IRB approval has been obtained for this study.

We decided to analyze senior design projects because these projects are the best reflection of students learning outcomes of their entire education program [20, 21]. By analyzing SDP's we are able to identify possible gaps between what students are producing as one of their most important projects in their academic program, and what is expected from them in industry. These gaps can provide us with data to guide SDP instructors in better aligning the content and delivery of the SDP courses.

\section{Setting and Participants}

We analyzed 52 senior design projects (SDP) in 4 different institutions: one large technical institute in the West coast (I\#1), one small private college in the Northeast (I\#2), one medium school in the Midwest (I\#3), and one large public land grant research university in the Southeast (I\#4). Each institution has an ABET-accredited industrial engineering program. In particular:

- I\#1 has an industrial engineering program with a high focus in manufacturing and processes improvement. We analyzed 6 SDP from this program.

- I\#2 has an industrial engineering and management program with a high focus in business, management, and economics. We analyzed 6 SDP from this program.

- I\#3 has a program in industrial and manufacturing engineering with a high focus on operations research and ergonomics and human factors. We analyzed 2 SDP from this program.

- I\#4 has a program in industrial and systems engineering with a high focus on applied operations research, human factors, and manufacturing. We analyzed 38 SDP from this program.

\section{Data Collection}

The reports, posters, and presentations of the past years (2015-2017) were collected across institutions. The sources of data obtained from these institutions were not comprehensive, yet because the study is exploratory, there are many valuable insights to be pursued further. To collect data, we reached out to 15 industrial engineering departments at institutions across the US. The point of contacts ranged from Faculty Capstone Advisers, to assistant professors, tenured professors, and department chairs. We specifically reached out to faculty who were involved with the senior design projects. The first round of recruitment emails yielded a $27 \%$ response rate. We 
reached out to a broad range of programs and focused our data analysis in the responses we received. The four institutions that provided material comprised a very different set of programs, through size and institution type (private, public, research etc.).

\section{Data Analysis}

The senior design project reports were analyzed after the projects were completed, with the use of the qualitative coding software, Nvivo11. Because, the analysis portion of the study was completed after the course had been completed and the students had graduated, we were unable to "cycle back and forth" between the data analysis and collection in order to avoid potential "blind spots" [22].

We applied descriptive codes consisting of phrases to larger sections of the text to condense the data into more manageable segments [22]. The analysis consisted of two stages of coding, first and second cycle coding. The first cycle codes consisted of characteristics of problems and solutions. The taxonomy in Table 1 was used. In the second cycle of coding, we coded for recurring themes such as a discussion of the environmental, societal, and ethical implications and instances of problem finding and problem framing. A detailed list of the coding dictionary with definitions and examples is provided in Table 2.

Table 1. Taxonomy of the characteristics of authentic problems and solutions

\begin{tabular}{|l|l|}
\hline Authentic Problem & Authentic Solution \\
\hline Problems were ill-structured & $\begin{array}{l}\text { The solution consists of a set of a recommendations, as } \\
\text { opposed to a single solution }\end{array}$ \\
\hline Problems required multi-disciplinary interactions & $\begin{array}{l}\text { The solution is provided in a stochastic form (e.g. } \\
\text { worst-case, base-case, nominal case) }\end{array}$ \\
\hline $\begin{array}{l}\text { Problems were provided by an actual client, with whom } \\
\text { the team had to interact during the project }\end{array}$ & $\begin{array}{l}\text { Needs are explicitly identified in the solution and the } \\
\text { solution addresses those needs }\end{array}$ \\
\hline & Unintended consequences of the solution are identified \\
\hline & The solution aligns with the client's objectives \\
\hline
\end{tabular}

In the second round of coding, we expanded on the predetermined codes to assign text to specific instances of the first round of codes. As an example, for ill-structured problems, we looked at instances of problem finding, problem reframing and scoping. The second round of coding helped identify detailed instances of how students interacted with clients, provided recommendations, discussed unintended consequences. Tables 2 and 3 list the first and second cycle codes with definitions and examples of what they represent. 
Table 2. First Cycle Coding and their Meanings

\begin{tabular}{|c|c|c|c|}
\hline Code & Definition & $\begin{array}{l}\text { Operationalized } \\
\text { Definition }\end{array}$ & Example \\
\hline $\begin{array}{l}\text { Actual } \\
\text { Client/Customer }\end{array}$ & $\begin{array}{l}\text { The senior design } \\
\text { project has a real- } \\
\text { world client or } \\
\text { customer. }\end{array}$ & $\begin{array}{l}\text { Mention of } \\
\text { client } \\
\text { interactions \& } \\
\text { communication }\end{array}$ & $\begin{array}{l}\text { "The company name is a collaborative } \\
\text { membership based organization that conducts } \\
\text { innovative manufacturing research. As the } \\
\text { company is quickly expanding, the need for a } \\
\text { formal overview of business operations was } \\
\text { becoming increasingly apparent." }\end{array}$ \\
\hline $\begin{array}{l}\text { Ill-structured } \\
\text { problems }\end{array}$ & $\begin{array}{l}\text { Problems that require } \\
\text { the refinement of } \\
\text { project objectives or } \\
\text { requirements }\end{array}$ & $\begin{array}{l}\text { Mention of } \\
\text { project scoping, } \\
\text { problem } \\
\text { defining, } \\
\text { framing }\end{array}$ & $\begin{array}{l}\text { "company name's customer base is growing and } \\
\text { current operations are not fit to meet the demand } \\
\text { of a growing company. More specifically, their } \\
\text { data management system can't be used by all } \\
\text { current employees to perform essential tasks } \\
\text { such as rental processing, bicycle and equipment } \\
\text { organization, and customer data analysis. This is } \\
\text { the origin and need for this project." }\end{array}$ \\
\hline $\begin{array}{l}\text { Multidisciplinary } \\
\text { interactions }\end{array}$ & $\begin{array}{l}\text { Projects that require } \\
\text { knowledge outside of } \\
\text { industrial engineering }\end{array}$ & $\begin{array}{l}\text { Students consult } \\
\text { non-IE experts, } \\
\text { or use non-IE } \\
\text { methods }\end{array}$ & $\begin{array}{l}\text { "Kiteboarding also takes place in salt water. The } \\
\text { salt water use required research on how } \\
\text { corrosion will affect the components of our } \\
\text { control system." }\end{array}$ \\
\hline $\begin{array}{l}\text { Students provide } \\
\text { recommendations }\end{array}$ & $\begin{array}{l}\text { Students offer } \\
\text { suggestions rather } \\
\text { than showing the } \\
\text { result of a calculation } \\
\text { on their solution }\end{array}$ & $\begin{array}{l}\text { Use of words } \\
\text { such as } \\
\text { recommend, } \\
\text { suggest, or } \\
\text { alternatives. Not } \\
\text { offering single } \\
\text { solutions }\end{array}$ & $\begin{array}{l}\text { "Five preliminary recommendations were } \\
\text { developed to help simplify company's room } \\
\text { reservation processes. The recommendations } \\
\text { each vary on a number of factors including } \\
\text { implementation time, complexity, and cost. } \\
\text { Each preliminary recommendation was aimed at } \\
\text { tackling an issue the team found during the data } \\
\text { analysis stage of the project." }\end{array}$ \\
\hline $\begin{array}{l}\text { Solution presented } \\
\text { in stochastic terms }\end{array}$ & $\begin{array}{l}\text { Solution is provided } \\
\text { with bounds (worst- } \\
\text { case, best-case, } \\
\text { expected), not in a } \\
\text { single number. }\end{array}$ & $\begin{array}{l}\text { Mention of } \\
\text { different bounds } \\
\text { for solutions. } \\
\text { (Use of the } \\
\text { words, best- } \\
\text { case, worst- } \\
\text { case, expected) }\end{array}$ & $\begin{array}{l}\text { "Figure } 3 \text { shows the results of our analysis } \\
\text { under three different scenarios. The projected } \\
\text { worst and best case savings range between } \\
\$ 475,000 \text { and } \$ 953,000 \text { per year with an } \\
\text { expected savings of about } \$ 866,000 \text { per year." }\end{array}$ \\
\hline $\begin{array}{l}\text { Unintended } \\
\text { consequences of } \\
\text { solution identified }\end{array}$ & $\begin{array}{l}\text { How did the solutions } \\
\text { they provide differ } \\
\text { from what they } \\
\text { intended? }\end{array}$ & $\begin{array}{l}\text { Mention of } \\
\text { limitations, } \\
\text { lessons learned, } \\
\text { things they } \\
\text { would have } \\
\text { done differently. }\end{array}$ & $\begin{array}{l}\text { "Double and triple check safety features! A } \\
\text { walker for an individual with limited mobility } \\
\text { must be } \\
\text { able to withstand jerky movement. After } \\
\text { fabrication and assembly, it was discovered that } \\
\text { the back hinge mechanism on the client's walker } \\
\text { would start to close should the walker user lean } \\
\text { left or right." }\end{array}$ \\
\hline
\end{tabular}




\begin{tabular}{|l|l|l|l|}
\hline $\begin{array}{l}\text { Lack of } \\
\text { identification for } \\
\text { unintended } \\
\text { consequences }\end{array}$ & $\begin{array}{l}\text { Solutions have not } \\
\text { identified } \\
\text { consequences are not } \\
\text { identified }\end{array}$ & $\begin{array}{l}\text { Lack of mention } \\
\text { of unintended } \\
\text { issues, }\end{array}$ & $\begin{array}{l}\text { This section has not been coded for yet, } \\
\text { however, will be included in the next draft } \\
\text { submission. These examples are generally those } \\
\text { consequences that fall outside of the scope of the } \\
\text { technical scope. }\end{array}$ \\
\hline $\begin{array}{l}\text { Solution needs } \\
\text { identified and } \\
\text { implemented }\end{array}$ & $\begin{array}{l}\text { Implementation needs } \\
\text { of their solution, } \\
\text { which affect the } \\
\text { effectiveness of the } \\
\text { solution, have been } \\
\text { identified in the } \\
\text { solution }\end{array}$ & $\begin{array}{l}\text { Mention of } \\
\text { solution's needs } \\
\text { that affect its } \\
\text { effectiveness }\end{array}$ & $\begin{array}{l}\text { "The quantifiable impact validated that the team } \\
\text { met, and in some cases, exceeded the measures } \\
\text { of success. However, the greatest impact that the } \\
\text { project accomplished cannot be measured. } \\
\text { These assistive technologies will improve the } \\
\text { client's ability to perform certain tasks and } \\
\text { ultimately improve his quality of life." }\end{array}$ \\
\hline $\begin{array}{l}\text { Effectiveness is in } \\
\text { line with client } \\
\text { objectives }\end{array}$ & $\begin{array}{l}\text { Valuation of the } \\
\text { effectiveness/goodness } \\
\text { of the solution is } \\
\text { consistent with the } \\
\text { objectives of the } \\
\text { client. }\end{array}$ & $\begin{array}{l}\text { Mention of } \\
\text { client objectives } \\
\text { when explaining } \\
\text { the solution }\end{array}$ & $\begin{array}{l}\text { "During the course of this project, the team was } \\
\text { in regular contact with the people that work } \\
\text { within the process and was given feedback as to } \\
\text { what could be improved and also gave feedback } \\
\text { when the changes were done to the process for a } \\
\text { short period in the pilot test. This information } \\
\text { was taken into consideration when making final } \\
\text { recommendations." }\end{array}$ \\
\hline
\end{tabular}

Table 3. Second Cycle Codes

\begin{tabular}{|l|l|l|l|}
\hline Code & Definition & $\begin{array}{l}\text { Operationalized } \\
\text { Definition }\end{array}$ & Example \\
\hline $\begin{array}{l}\text { Environmental, } \\
\text { societal, and } \\
\text { ethical } \\
\text { implications }\end{array}$ & $\begin{array}{l}\text { Students discussing } \\
\text { implications of } \\
\text { their solutions that } \\
\text { extend beyond } \\
\text { technical analysis. }\end{array}$ & $\begin{array}{l}\text { Mention of } \\
\text { environment, } \\
\text { societal, or ethical } \\
\text { implications }\end{array}$ & $\begin{array}{l}\text { "Reducing bars being shipped back from } \\
\text { consumer, to retailers, and from retailers back to } \\
\text { the company not only cuts costs for the company, } \\
\text { but also less environmental impacts due to } \\
\text { shipping." }\end{array}$ \\
\hline $\begin{array}{l}\text { Problem } \\
\text { framing }\end{array}$ & $\begin{array}{l}\text { Projects that } \\
\text { redefine the } \\
\text { problem such that } \\
\text { they can focus on } \\
\text { specific aspects. }\end{array}$ & $\begin{array}{l}\text { Report exhibits a } \\
\text { larger focus on } \\
\text { understanding and } \\
\text { probining the }\end{array}$ & $\begin{array}{l}\text { "Understanding the process by observing it from } \\
\text { beginning to end helped the team define the } \\
\text { process steps, which helped with data collection } \\
\text { and finding what elements to time. It also helped } \\
\text { in seeing that some steps within the process could } \\
\text { be combined as with the extractor step and first } \\
\text { label. The current process has the plasma being } \\
\text { extracted and then going to a separate labeling } \\
\text { station." }\end{array}$ \\
\hline Problem finding & $\begin{array}{l}\text { Students include } \\
\text { problems they find } \\
\text { by interacting with } \\
\text { client. }\end{array}$ & $\begin{array}{l}\text { Mention of } \\
\text { problems in } \\
\text { addition to main } \\
\text { problem statement. }\end{array}$ & $\begin{array}{l}\text { "Another problem stemming from a lack of an } \\
\text { automated location system is bus routing logistics. } \\
\text { Because specific buses can't be located, buses } \\
\text { leave the facility in a first-in first-out method. This } \\
\text { leads to improper usage of fuel and bus types" }\end{array}$ \\
\hline
\end{tabular}




\section{Results}

The codes have been aggregated in a visual shown in Figure 1. The size of the shapes represents the number of times that each code was referenced in the data. For instance, students described attributes of the problem domain more than they did those of the solution domain. Many projects had an actual client as a stakeholder in the project, but few reports included a literature review. The category lack of unintended consequences was difficult to code for without more sources of data from the client and student team. Only the most evident issues were coded. Recommendations were largely provided in the reports, but when looking deeper at examples, the students often only provided one recommendation, which may well have been one solution. Further investigations into the specificities of these categories will be needed before drawing generalizable claims about senior design projects.

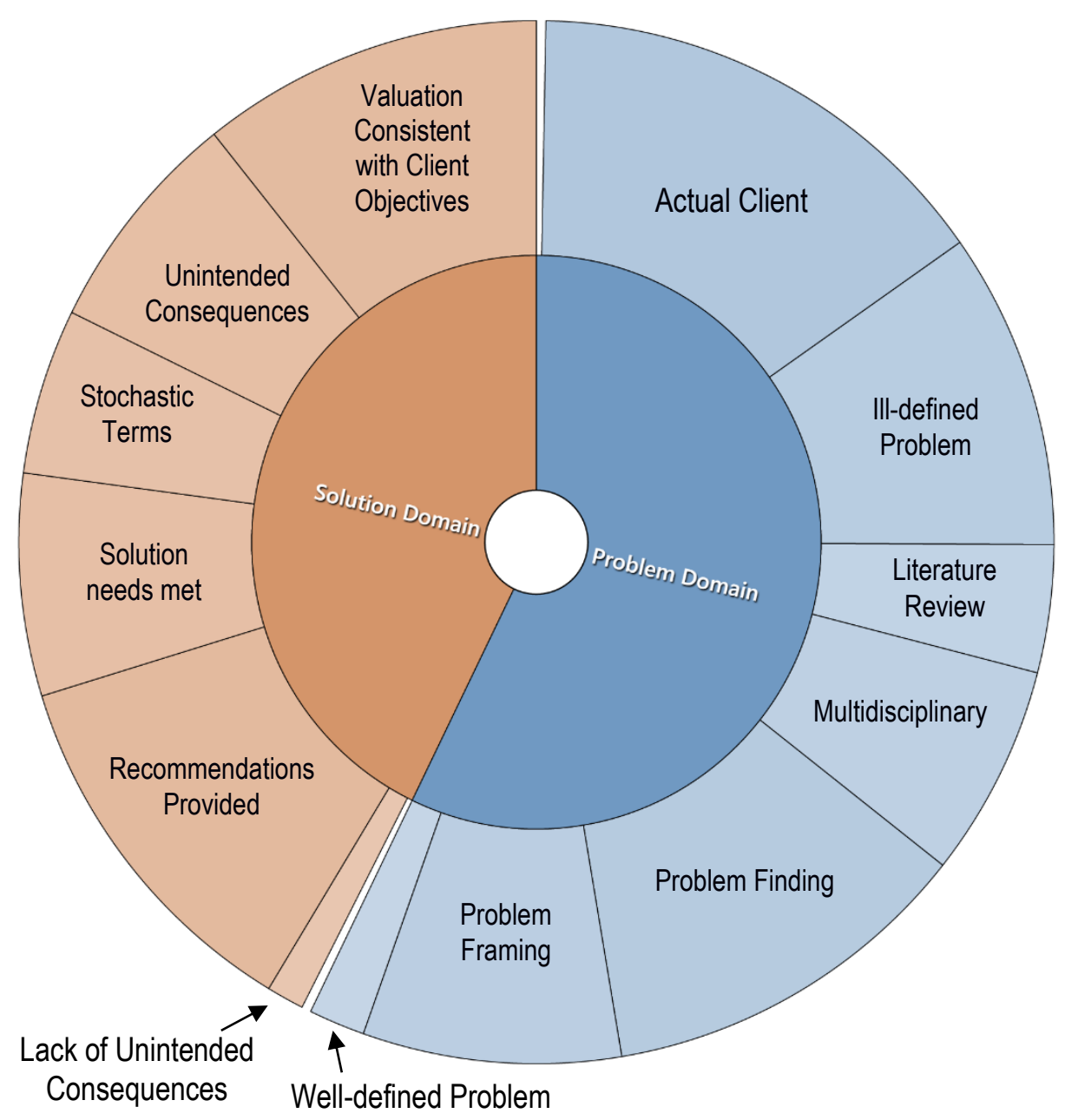

Figure 1. Visual Representations of Findings

From the data analysis, we noted several themes across the senior design projects. Even though the overarching structure of the reports were similar, there were differences in the details of each of the sections. The high-level themes we focused on were authenticity of the problems, authenticity of the solution, and the reach beyond the project (for instance, ethical issues). These 
themes were composed of specific aspects of each theme (eg. ill-structured problem, unintended consequences of the solution).

One notable distinction in the problem domain was the difference in how teams defined their ill-structured problems. Some reports provided a rich explanation and exploration of the problem space that they strengthened with a literature review. There were teams who provided an overall goal in response to their problem with more specific objectives that included efforts to define the problem. One objective a team put forth was "to research location technologies to make an educated decision about which one best meets [the client's] needs." In contrast, other projects focused more on describing the methods they used to solve the problem rather than uncovering aspects of the problem that lay outside of the prompt. One group provided a brief problem statement (short paragraph), and then proceeded to explain how they used process mapping, a "tool used to get a clearer understanding of the process as a whole by using a workflow diagram." With process mapping, this group identified "non-value-added processes" to get a "high level overview of the process." The main concern with the use of this tool is that the team failed to incorporate other measures to ensure that those "non-value-added processes" had no other benefits to the system that were not clear through process mapping. By relying solely on this tool, the team may have had oversimplified their problem without fully understanding its complexities. Within these instances, a variety of methods is necessary to first define, and then scope the problem such that potentially critical aspects of the problem's authenticity are not overlooked.

Overall, across institutions, instances of problem finding did not follow a similar trend. Problem finding, in which students identified problems in relation to their overarching problem, was not common across all institutions. In fact, they seemed to differ based on the geographic location of the university. Many of the senior design teams had clients that were local to their area, which could be limiting if some of those areas are on the smaller and more rural side. The geographic limitation shows an apparent relationship with the level of depth in problem definition the senior design teams display in their projects. Because this study is exploratory, geographic location as an influencer of problem definition would need to be investigated further.

In addition, there were differences in the reports that had a client who was more involved in the design team. Specific to this finding, there was a difference among the reports that had teams working with someone with a disability. Of the sample size, two design projects worked with individuals with disabilities. The reports were from teams at different institutions, but had very similar qualities. These teams reported to have worked much closer with their clients, and the quality of their work reflects a more holistic understanding of their clients' situations. There was a sense of deliberate problem definition and solution that showed the project's effectiveness to be in alignment with the client's objectives. We speculate that having a real client involved in the design project, whom students could have ongoing interactions with benefit to the way they approached the problem, and to the consequent interrelatedness of the information presented. Nevertheless, we cannot confirm this claim with our data.

With regard to how the students discussed the authenticity of their solutions, we noted several distinctions across reports. The majority of student teams provided recommendations rather than a single solution. Generally, those who provided a single solution were teams that had built a physical prototype. Yet even those who did provide recommendations, they stated them as 
"recommended solutions." One student's recommendation was to "recommend the operating manager to implement all 6 recommendations," where each recommendation took the form of a solution to each problem.

In terms of stochastic thinking, only one of the fifty-two reports presented their work in stochastic terms, to include a best-case, worst-case, nominal-case scenario. This team "decided to make a worst-case budget so that the recommendations would be sustainable through the future." Stochastic terms provide added context for the client as well as strengthen the team's ability to conceptualize aspects of the problem that may not have been fully realized, for instance, unintended consequences.

Unintended consequences of the solution were discussed by only a few student teams. Notably, the teams with access to workshop machinery paid far greater attention to these unforeseen issues, through images and explanations on how they changed direction with their projects. In one example, the team was working on a "footrest frame ... attached to the chair" for them "it quickly became obvious that [the client] would need some sort of foam padding in order to make it a more comfortable fit." They went on to explain that "through many prototyping sessions, the team and [the client] decided together that a U-shaped piece of foam was needed to encircle the lower portion of his leg and under his foot." In the instances where students had direct feedback from their client and from the physical nature of their prototypes, they were quick to change their products. Iterations and prototyping were far more prevalent among the groups who were making physical objects than among those designing processes or systems. Perhaps this is due to the ongoing feedback these groups received or the ability for teams to use artifacts through their designs, thus contributing to better communication across the team and with the client. Yet, this study cannot draw conclusions on whether access to machinery or ongoing client feedback resulted in a better understanding of unintended consequences, but it can shed light on the trends seen across reports.

Lastly, any mention or exploration of societal, ethical, and environmental implications of their solutions were seemingly absent from most of the senior design reports. Some reports included a short paragraph that mentioned cost reductions that would reduce an environmental footprint, but these remarks were not common across institutions -only two of the five institutions had reports that included these sections. However, these still lacked depth and some even went so far to say that their solution had no environmental, societal, or ethical implications.

\section{Limitations}

In addition to the limitations identified in the previous section, the data collection in this study was limited due to the range of institutions that provided senior design reports. Moreover, the number of reports provided were not uniform across the universities. Some institutions provided reports from just one academic year and others provided several across a few academic years.

Furthermore, our team only received the final product the students created after completing their project. Additional information surrounding the student processes throughout their project or regarding initial prompts from the client would have been beneficial in providing more context 
with how the teams arrived at their findings. Moreover, many of the teams had contacts with faculty and clients during the execution of their projects. Such input could have shed light on the project as well. Yet, since the purpose of this study was to conduct an exploratory study of senior design projects, these additional sources of data were not collected. They will be considered in further investigations though.

Furthermore, in some cases we only had a data point. That means that for some institutions we only had one project to evaluate. As a result, we are not able to generalize the results presented in this paper to be representative of the typical SDP's for that institution.

From the data gathered however, we have several avenues of future investigation; such that unpacking potential effects that machinery access, geographic location of the projects, or ongoing client feedback have on student teams. These results have highlighted several areas, in which to position future studies.

\section{Discussion}

This exploratory study has offered several insights into SDP deliverables and suggests several avenues to continue the research. The analysis of industrial engineering senior design deliverables has shown the areas that students pay more attention to and those that perhaps need revisiting. In many of the problem statement explanations, students used tools from their industrial engineering background to better understand the issue at hand. However, this may have limited the breadth in which they explored the problem space. For instance, process mapping was used in several instances to "get a clearer understanding of the process as a whole by using a workflow diagram," but of those reports that used these tools, students used far less detail in defining and outlining the problem. Problem definition or problem setting, as mentioned above, necessitates that students first understand the nature of the problem before beginning its solution. There is a level of contextual information that cannot be deduced without spending time defining the problem [13]. When solving any problem, there are hidden assumptions that must first be identified. Problem definition is the stage in which this should occur.

The majority of student teams did not include multidisciplinary interactions in their work. The teams that were comprised of different engineering disciplines showed more multidisciplinary interactions because it was embedded in their teams. However, within these groups those that had experience in different disciplines worked on aspects of the project that fit their skill set [23]. All of these multidisciplinary teams used the 'divide and conquer' method of delegating tasks. As an example, one group scoped their project with respect to the disciplines in their team. Specifically, for "the ISE (Industrial and System Engineering) members of the team, the scope of the project is limited to the ergonomic analysis, design and human factors work associated with creating and building these products. The ME (Mechanical Engineering) students were focused on the mechanics and actual building process of the project." This approach breaks holism. It remains unclear whether the students learned aspects of one another's discipline from this project, or even learned how to integrate diverse knowledge. Because of the seemingly insular group work the students used, their collaborative work may not be more than a combination of individual projects. Even though the knowledge required to work on engineering problems may be technical, the social interactions are what make products successful [24]. 
The multiple perspectives that come with multidisciplinary interactions may have also influenced unintended consequences identified by teams. Not many teams included explanations of the unforeseen issues related to their solutions. Of those that did, there was a pattern however. The teams that had access to workshop machinery or worked with a physical prototype wrote much more in depth aspects about the unintended aspects of their solutions. For example, one group working on building a metal walker had to undergo multiple tries before achieving an acceptable solution. Their first attempt "failed because even after the annealing the metal was strong when cooled to bend. The second attempt was more successful." Another group, spoke of the instant feedback they received on their prototype; with "the addition of the buckle straps, it quickly became noticeable that the polyester could become irritating to [the client's] skin by rubbing up against his feet and ankles. The team explored options and chose the solution of adding fleece noseband covers which are frequently used on a horse's halter." The instant feedback received from the physical materials in the first example and the client's skin reaction in the second example are clear indicators to the groups that they needed to revise their work. Perhaps, it was the clarity of this feedback that resulted in their discussion and revision in their solution. However, the thinking in unintended consequences was not exhibited, since they were discovered by prototyping instead of by conceptual exploration. For other projects that devised simulations or models, discussion of unintended consequences was not included in the reports. One possibility is that they were not as instrumental in shaping their final solution or another is that their solution was not implemented such that they could see how well it worked to be able to add revisions afterwards. In any case, this demonstrates that students were not able to frame the solution realistically.

The level of client interaction mentioned in the report was another theme that had apparent trends in the thoroughness of the project. The background and literature review sections in these projects were very extensive and included a more holistic description of the problem. From including explanations on the legal restraints, technical possibilities, human factors, societal implications, teams with a heavily involved client showed greater depth in their problem definition. The client may have had a direct influence on where the team looked in their research pertaining to the project, thus resulting in a more comprehensive overview of what their project entailed.

For those clients who embodied the 'problem,' projects had a different level of personal involvement, in which the student teams used a different language. There was a sense of connection and emotion in these reports. Moreover, many of the decisions made in these groups were a yes or no decision, in that the design would or would not work with the client. Because the team's design directly affected one person, this instant feedback may have been a critical element in establishing the report as decisive. As an example, one report explains their choice for a certain design based on how the client's "currently uses the U-shape for her forearms and prefers this armrest to the other armrests she has had in the past. Because this is something the team already knows she likes, the design was kept the same." The personable element is always at the forefront in this project, which may explain, at least partially, the differences in how this report reads.

\section{Guidelines for a SDP rubric}

The aim of this exploratory study is to serve as a pilot of a larger researcher project. Yet, it provided us already with insights on how students from different institutions approached SDP's that can inform the refinement of SDP rubrics. Based on the results presented in previous sections, 
we suggest that the following guidelines for developing a rubric will be effective not only in capturing student learning of technical aspects of the design, but also how well students are regarding other realistic expectations that industry has from them as future practicing engineers:

- One important aspect to evaluate in SDP's is how students consider the actual client/customer, not only as stakeholders that provide valuable input regarding their needs, who will be used to create an effective design, but also to provide contextual aspects of the problem that will impact the way solutions are considered and implemented. For example, solutions should be presented as ratios or percentages with respect to success targets, instead of as absolute figures.

- Another aspect to evaluate is the process by which students frame, define, and operationalize the problem. Students need to be able to go through a complete process of problem identification and formulation in order to develop their design process plan.

- Senior and capstone design courses should be able to provide a safe space for students to accept uncertainty and embrace ambiguity

- . Uncertainty avoidance is something engineering students must avoid to be able to deal with the unexpected and fast-pacing demands of industry [25]. Hence, it is important to evaluate to what degree students can face ill-structured problems and feel comfortable dealing with them.

- Every design project, no matter the problem or the context, will require designers to look for information outside their disciplinary boundaries. Solving a problem requires many fields' interactions at many different levels. Another aspect that we should consider in the assessment of SDP's is how well students understand the importance of using disciplinary content outside of industrial engineering in their work, such that they incorporate and even collaborate with other fields.

- As mentioned, SDP's must be presented in stochastic terms. We suggest using ranges that go from worst-case to best-case, and that students are assessed in their ability to understand the factors that impact the different ranges, not only technical but also contextual.

- Senior industrial engineering students should have the skills, moral development and ethical understanding of the impact of their designs, especially considering environmental and societal perspectives. Students must be able to understand the unintended consequences of their proposed solutions, and how those consequences play into their decision-making process.

\section{Conclusion}

Undergraduate senior design projects are generally intended for students to put their knowledge from the engineering curriculum into practice by working on a real-world problem. The exploratory study was conducted to bring attention to some of the reality gaps that occur for students when they begin to transition from theory to practice. From this study, several gaps have been identified and warrant further investigation into their contributing factors. Authentic engineering education is difficult to achieve in four years and we believe that it requires several major changes across the engineering curriculum. However, we suggest that using the proposed guidelines may help in closing the gap between engineering theory and real-world engineering at least in SDP's. As a result, we believe that such SDP experiences would result in students better 
prepared to address problems that do not have one clear solution and are across multiple disciplines.

\section{Future Work}

This exploratory study allowed us to have some insight on senior design students' outcomes from different institutions and we consider is a great starting point to expand our research. We aspire to get more industrial engineering programs involved in the next steps of our research so we can get a better sense of what students are doing across the country. Furthermore, we want to incorporate different points of information in our research that include not only SDP's final reports, but also to analyze presentations, prototypes, course content, student and faculty feedback, peer review processes. In addition, we plan to develop a rubric that can be standardized, piloted, and validated to measure different constructs that we consider relevant to industrial engineering design so it can be generalized and applied by many faculty members teaching senior capstone design in the United States.

\section{References}

[1] A. Johri and B. M. Olds, "Situated engineering learning: Bridging engineering education research and the learning sciences," Journal of Engineering Education, vol. 100, no. 1, pp. 151-185, 2011.

[2] S. R. Brunhaver, R. F. Korte, S. R. Barley, and S. D. Sheppard, "Bridging the gaps between engineering education and practice," in US Engineering in a Global Economy, Chicago: University of Chicago Press, 2016.

[3] G. A. Hazelrigg, "A framework for decision-based engineering design," Journal of Mechanical Design, vol. 120, no. 4, pp. 653-658, 1998.

[4] V. A. Lagesen and K. H. Sørensen, "Walking the line? The enactment of the social/technical binary in software engineering," Engineering Studies, vol. 1, no. 2, pp. 129-149, 2009.

[5] J. Trevelyan, "Reconstructing engineering from practice," Engineering Studies, vol. 2, no. 3, pp. 175-195, 2010.

[6] B. Williams, J. Figueiredo, and J. Trevelyan, Engineering practice in a global context: Understanding the technical and the social. London: Taylor \& Francis, 2014.

[7] D. H. Jonassen, "Engineers as problem solvers," Cambridge handbook of engineering education research, pp. 103-118, 2014.

[8] A. Salado, J. R. Morelock, and A. B. Lakeh, "Decision-Making, Information Seeking, and Compromise: A Simulation Game Activity in Global Industrial Management.," in Paper presented at the 2017 ASEE Annual Conference \& Exhibition, Columbus, OH, USA., 2017, pp. 129-149.

[9] N. J. McNeill, E. P. Douglas, M. Koro-Ljungberg, D. J. Therriault, and I. Krause, "Undergraduate Students' Beliefs about Engineering Problem Solving," Journal of Engineering Education, vol. 105, no. 4, pp. 560-584, Oct. 2016.

[10] T. Litzinger, L. R. Lattuca, R. Hadgraft, and W. Newstetter, "Engineering Education and the Development of Expertise," Journal of Engineering Education, vol. 100, no. 1, pp. 123-150, Jan. 2011.

[11] D. Ferguson and M. W. Ohland, "What is Engineering Innovativeness?," Engineering in K-12 Education, vol. 28, pp. 1-35, 2009. 
[12] D. A. Schön, Educating the reflective practitioner: Toward a new design for teaching and learning in the professions. Jossey-Bass, 1987.

[13] J. A. Leydens and J. C. Lucena, "Social Justice: A Missing, Unelaborated Dimension in Humanitarian Engineering and Learning Through Service.," International Journal for Service Learning in Engineering, vol. 9, no. 2, 2014.

[14] D. Grasso and D. Martinelli, "Holistic Engineering BT - Holistic Engineering Education: Beyond Technology," D. Grasso and M. B. Burkins, Eds. New York, NY: Springer New York, 2010, pp. 11-15.

[15] G. L. Downey et al., "The Globally Competent Engineer: Working Effectively with People who Define Problems Differently," Journal Engineering Education, pp. 107-122, 2006.

[16] G. L. Downey, "The Normative Contents of Engineering Formation," in Cambridge Handbook of Engineering Education Research, A. Johri and B. M. Olds, Eds. Cambridge: Cambridge University Press, 2014.

[17] R. Straubhaar, "The stark reality of the 'White Saviour'complex and the need for critical consciousness: A document analysis of the early journals of a Freirean educator,"

Compare: A Journal of Comparative and International Education, vol. 45, no. 3, pp. 381400, 2015.

[18] D. M. Riley, "Social Justice and Engineering," Synthesis Lectures on Engineering, Technology, and Society, vol. 7, no. 1, 2008.

[19] J. Lucena, J. Schneider, and J. A. Leydens, "Engineering and sustainable community development," Synthesis Lectures on Engineers, Technology, and Society, vol. 5, no. 1, pp. 1-230, 2010.

[20] A. J. Dutson, R. H. Todd, S. P. Magleby, and C. D. Sorensen, "A Review of Literature on Teaching Engineering Design Through Project-Oriented Capstone Courses," Journal of Engineering Education, vol. 86, no. 1, pp. 17-28, 1997.

[21] ABET, "Criteria for accrediting engineering programs: Effective for reviews during the 2015-2016 accreditation cycle," Accreditation Board for Engineering and Technology Engineering Accreditation Commission, 2014.

[22] M. Miles, M. Huberman, and J. Saldana, "Fundamentals of Qualitative Data Analysis," in Qualitative Data Analysis - A Methods Sourcebook, 3rd ed., 2014, pp. 69-103.

[23] L. D. McNair, C. Newsander, D. Boden, and M. Borrego, "Student and faculty interdiscipinary identities in self-managed teams," Journal of Engineering Education, vol. 100, no. 2, pp. 374-396, 2011.

[24] D. Vinck, "Socio-Technical Complexity: Redesigning a Shielding Wall," in Everyday Engineering: An ethnography of Design and Innovation, 2003, p. 13-.

[25] H. G. Murzi, T. Martin, L. D. McNair, and M. C. Paretti, "Comparative Dimensions of Disciplinary Culture," in ASEE Annual Conference \& Exposition, 2015. 